

U. S. Department of Commerce Daniel C. Roper, Secretary National Bureau of Standards Lyman J. Briggs, Director ono

Visitors' Manual of the

National Bureau of Standards

A Brief Synopsis of Its History, Functions, and Laboratory Facilities

Miscellaneous Publication M153

(Supersedes Miscellaneous Publication M134)

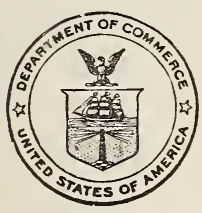




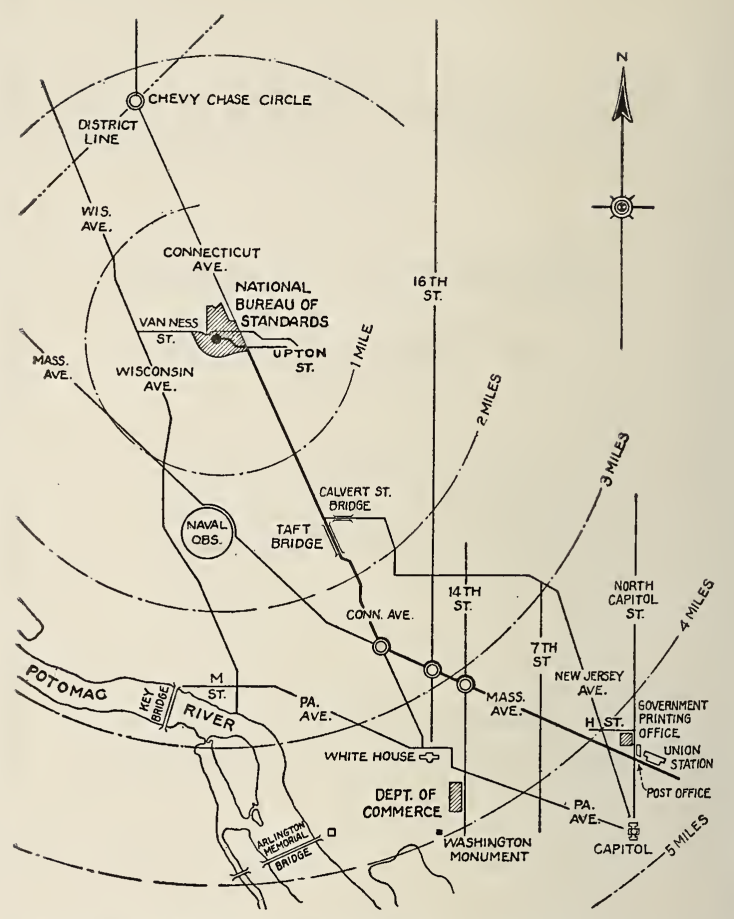

Location of the National Bureau of Standards in relation to a few of the principal streets and public buildings. 


\section{VISITORS' MANUAL OF THE NATIONAL BUREAU OF STANDARDS 1}

\section{CONTENTS}

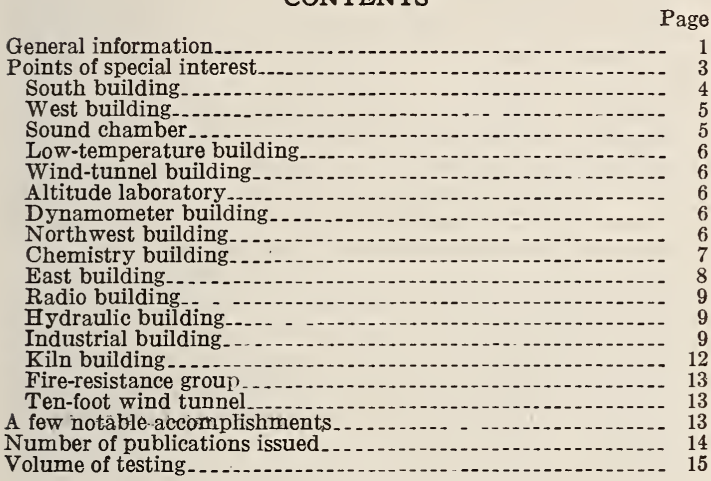

\section{GENERAL INFORMATION}

History and functions-The National Bureau of Standards was established by act of Congress, approved March 3,1901, continuing the duties of the old Office of Standard Weights and Measures of the Coast and Geodetic Survey. In addition, new scientific functions were assigned to the new Bureau. Originally under the Treasury Department, the Bureau was transferred in 1903 to the Department of Commerce and Labor (now the U. S. Department of Commerce). It is charged with the development, construction, custody, and maintenance of reference and working standards and their intercomparison, improvement, and application in science, engineering, industry, and commerce.

Statistics-The original staff numbered 14 and the laboratories were housed in temporary quarters near the United States Capitol. There are now about 700 employees, two-thirds of whom are scientifically

1 Prepared by Hugh G. Boutell, Chief, Information Section.

$142728-35$ 
and technically trained. The director of the Bureau is Dr. Lyman J. Briggs. The laboratories occupy 12 major and 7 minor buildings on a site of 56 acres, situated at the intersection of Upton Street and Connecticut Avenue in the northwest suburbs of Washington, 4 miles northwest from the Washington Monument. The altitude of the lower floor of the north building is 335.69 feet above mean sea level, latitude $38^{\circ} 56^{\prime} 32^{\prime \prime}$ north, longitude $77^{\circ} 03^{\prime} 59^{\prime \prime}$ west.

Those desiring other general information about the Bureau may telephone Cleveland 1720, branch 230.

Research associates-In addition to the regular staff, there are at the Bureau a number of research associates, supported by industrial groups to work on research problems of mutual interest to the Bureau and the industry concerned. Their status is that of a Bureau employee. Results of the work of research associates are public property.

Organization-The Bureau is organized in three principal groups-the first dealing with research and testing; the second with commercial standardization; and the third with the administrative work, operation of plant, and construction of laboratory apparatus. There are 9 divisions of the first group, made up of 67 sections; 3 divisions with a total of 14 sections in the second group; and 3 divisions containing 19 sections in the third group.

Services-The Bureau's services are available to the National and State Governments without charge. Work other than that for the Government is undertaken under certain conditions, the main consideration being the value of the work to the Nation as a whole. For private tests a fee is charged, which, however, is turned into the United States Treasury and is not available to the Bureau.

Publications-The results of the Bureau's investigations are made available through its own publications and by articles in the scientific and technical journals. Several series of publications are issued by the Bureau covering various phases of the work. A list of these may be purchased for 40 cents from the Superintendent of Documents, Government Printing Office, Washington, D. C.

Results of original research are published monthly in the Journal of Research of the National Bureau of Standards, obtainable on a subscription basis at $\$ 2.50$ per year ( $\$ 3.25$ foreign). Semiannual volumes of the Journal of Research bound in cloth may also be purchased from the Superintendent of Documents at $\$ 3$ per volume. The various papers 
in the Journal are also published separately as Research Papers. These are numbered consecutively, as RP1, RP300, etc.

Progress of work in the laboratories, important conferences, and new publications issued can be followed in the Technical News Bulletin, issued monthly and obtainable by subscription at 50 cents per year (70 cents foreign) from the Superintendent of Documents.

Nonperiodical publications include Circulars, containing compiled information on scientific and technical subjects; Handbooks, usually containing weights and measures regulations, safety codes, and similar recommended laws, standards of practice, and regulations; Simplified Practice Recommendations, consisting of approved elimination of superfluous sizes and varieties of articles in common use; Building and Housing publications, covering recommended requirements for building codes, homeowner's problems, and related matters; Commercial Standards, giving acceptable standards of quality agreed to by manufacturers, distributors, and consumers; and Miscellaneous Publications, generally compiled data, charts, etc., that do not fit into the other series. None of these publications is available on a subscription basis.

\section{POINTS OF SPECIAL INTEREST}

The laboratories in the following list have been chosen as of greatest interest to the majority of visitors. Likewise they are representative of the Bureau's work, which includes fundamental and applied research and testing.

Special arrangements can be made to visit other laboratories not listed.

Visitors' trip-A scheduled trip through the laboratories for general visitors starts from room 300 , South Building, at 1:45 p. m., daily, excepting Saturdays, Sundays, and holidays. Special arrangements must be made several days in advance for groups of 10 or more. It is possible, on any one trip, to visit only a few of the places listed. In the case of a small group, the guide tries, as far as possible, to accommodate the interests of those making the trip but the visitor with some definite interest should go to the laboratory concerned rather than on the general trip. The Bureau is open for official business from 8:30 a. m. to 4:00 p. m. $(12: 30$ p. m., Saturday). The sequence of buildings here given is that in which the trips are ordinarily routed. 


\section{SOUTH BUILDING}

Room 101-Mass section

Weights of many different classes are compared with the Bureau's standards in this laboratory. The balances used in this work include several of the highest precision. One of these is a large balance for comparing 50-pound weights with an error of only 1 part in 20 million. This section has the custody of the national standard of mass, obtained from the International Bureau of Weights and Measures.

Rooms 108 and 109-Dimensional variations

Investigation of dental materials; thermal expansivity of solids over a wide range of temperatures. Room 114 and corridor-Interferometry

A demonstration apparatus is arranged to show the bending of a 5-inch steel bar under the pressure of a finger. Optical methods are employed by the Bureau in making all sorts of precision length measurements. The equipment of this laboratory includes apparatus for ruling scales directly from light waves.

Room 116-Identification of questioned documents, guns, and bullets

Special arrangements must be made with the section chief to inspect the identification work.

Rooms 201 and 202-Capacity and density

Tests of glass volumetric apparatus and hydrometers; determination of density and thermal expansion of liquids.

Room 209-Length measurements

In this laboratory length-measuring instruments of all kinds are checked against the working standards of the Bureau. These in turn have been compared with the national standard, which is kept in the vault on the first floor of this building. High precision length measurements are made in a special underground room, where temperature is practically constant. (Open only by special arrangement when no work is in progress.)

\section{Room 212-Spectroscopy}

In this section the spectra of the elements are photographed, and the position and intensity of the lines determined with high precision, thus furnishing reference standards for the science of spectroscopy. The spectra of rare gases occurring in the atmosphere may be viewed through a small spectroscope. 
SOUTH BUILDING-Continued

\section{Room 218-Time section}

Watches and clocks are here compared under controlled conditions with the Bureau's standard clocks, which are installed in a special room in the basement. These clocks do not vary more than 2 one-hundredths of a second per day.

\section{WEST BUILDING}

\section{Room 102-Engineering instruments}

Pressure gages, liquid meters, anemometers, and fire extinguishers are among the instruments and appliances tested in this laboratory. A standard test for elevator interlocks was developed by this section.

\section{Room 203-Testing of thermometers}

Mercury-in-glass thermometers are compared with the Bureau's standards by immersing both instruments in a bath, the temperature of which can be kept at any desired point.

\section{Room 212-Pyrometry}

Devices for measuring high temperatures are tested in this laboratory. These include thermocouples, and optical and radiation pyrometers. The apparatus and method necessary for the realization of a new absolute standard of light (the Waidner-Burgess standard) were developed in this section.

\section{Room 306-Optical testing of sugar}

The standard test for purity of a sugar solution is made by means of an instrument known as a "saccharimeter." This instrument measures the rotation of a beam of plane polarized light passing through the solution. The Bureau also carries out research work on the properties of sugar. By special arrangement with the United States Treasury Department, the Bureau supervises the equipment and methods used in testing sugar at the Customs laboratories, which are located at the various ports of entry.

\section{SOUND CHAMBER}

Transmission and absorption and reverberation of sound in rooms by acoustical building materials are studied. A revolving loud-speaker is used as the sound source in the reverberation chamber and will be demonstrated by special arrangement. 


\section{LOW-TEMPERATURE BUILDING}

The discovery of deuterium (heavy hydrogen) was the result of cooperative work of this laboratory with Columbia University. Here, the lowest temperature so far attained in this country, that of liquid helium $\left(-456^{\circ} \mathrm{F}\right)$, has made possible the study of the properties of materials at very low temperatures, particularly superconductivity in metals. Liquid air (temperature $-310^{\circ} \mathrm{F}$ ) is usually on hand and its effect on the properties of common materials can be demonstrated.

\section{WIND-TUNNEL BUILDING}

Main laboratory-Aerodynamics

One of the three wind tunnels at the Bureau, employed in studying the characteristics of air flow in the tunnel itself and the behavior of model airplanes, automobiles, bombs, buildings, chimneys, etc., in an air stream. This tunnel is 54 inches across at smallest section, and in it a wind speed of 75 miles per hour can be attained.

\section{ALTITUDE LABORATORY}

Studies of airplane engine performance under flight conditions. The low air pressures and temperatures encountered at altitudes up to 30,000 feet can be duplicated.

\section{DYNAMOMETER BUILDING}

\section{Main laboratory-Automotive power plants}

Investigation of performance of internal-combustion engines with special reference to fuels, lubricants, and devices intended to promote economy and efficiency.

\section{NORTHWEST BUILDING}

Basement-Experimental foundry and metal-working equipment

Alloys can be prepared by melting in induction, electric-arc, or gas-fired furnaces, and cast, rolled, forged, or drawn into the shape desired. The equipment employed is similar to that used in actual mill practice but on a smaller scale.

Room 105-Microstructure of metals

The crystalline structure of metals and alloys is studied in this laboratory. The effect of work, heat treatment, corrosion, etc., can be determined. 
NORTHWEST BUILDING-Continued

Room 202-Gages

Testing of precision gages used for controlling the dimensions of machine parts. Optical methods are often used in testing gages, and their lengths can be determined to one-millionth of an inch.

Room 311-Aeronautic instruments

Testing of all types of aeronautic instruments for scale errors, effect of temperature and pressure, elastic defects, vibration, and other factors affecting the performance of these instruments. Fundamental research and a certain amount of development work on special instruments are also being carried on.

\section{CHEMISTRY BUILDING}

Room 8-Electrochemistry

Small electroplating plant, used for preparing specimens for exposure and laboratory tests.

\section{Room 112-Electrochemistry}

Equipment for measuring conductivity and hydrogen-ion concentration.

\section{Room 205-Gas chemistry}

Equipment used in the testing of gas appliances, including several devices for the rapid analysis of products of combustion and of mixtures being burned, which are of interest to those engaged in the study of the utilization of gas.

Room 208-Gas chemistry

Here will be seen a considerable variety of apparatus for the analysis of gases, especially some very well-designed equipment for volumetric analysis, and elaborate apparatus for the fractionation of gases by distillation.

Room 211 and shaft in corridor-Petroleum

Laboratory stills for determining the chemical composition of petroleum.

Room 303-Organic chemistry

Pure crystalline rubber has been produced in this section.

Room 410-Accelerated weathering equipment for organic protective coatings

Apparatus for determining breakdown of protective coatings.

Apparatus for determining hiding power of paint. 


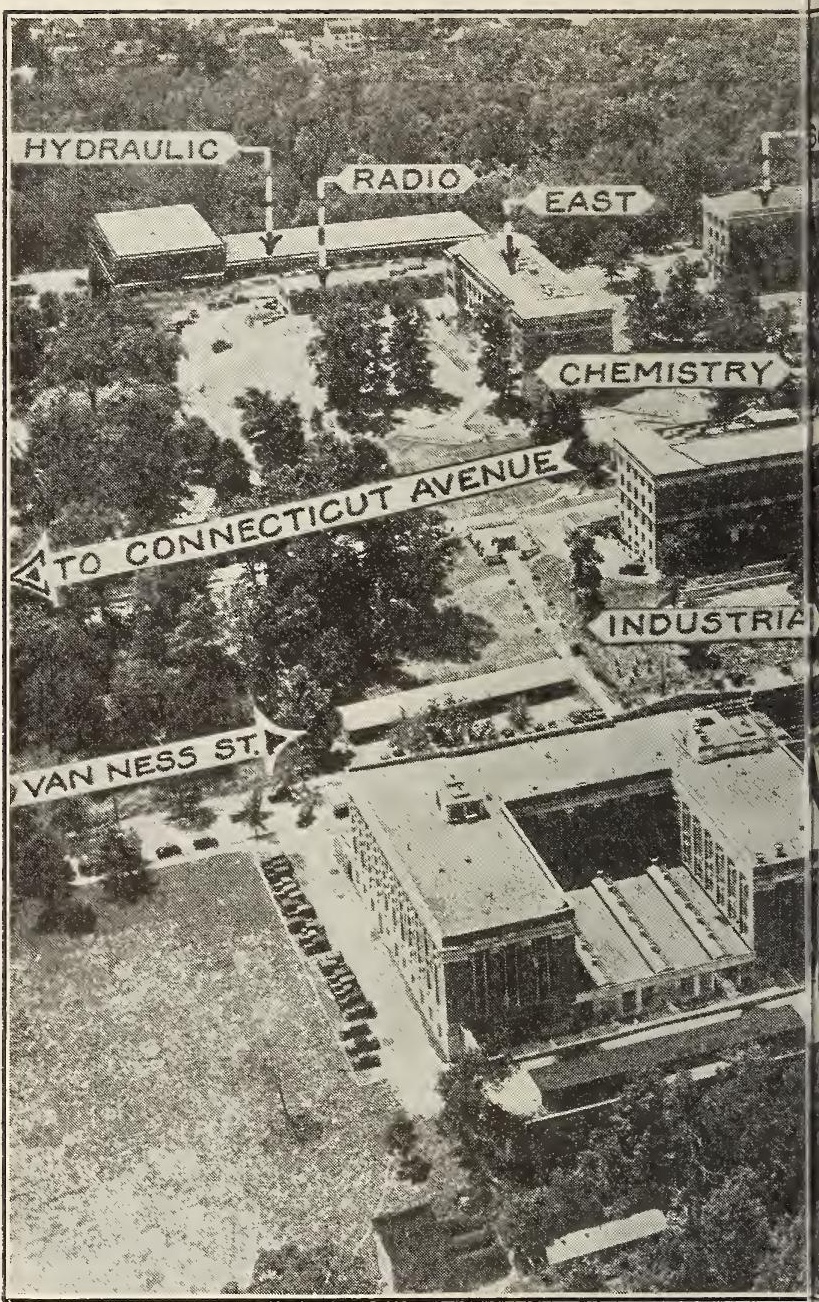

Airplane view of the $\mathrm{Na}$

[Look.

The names of the principal buildings are shown. The main entrance to tr trip through the laboratories starts at 1:45 $\mathrm{p}$. $\mathrm{m}$. fror 


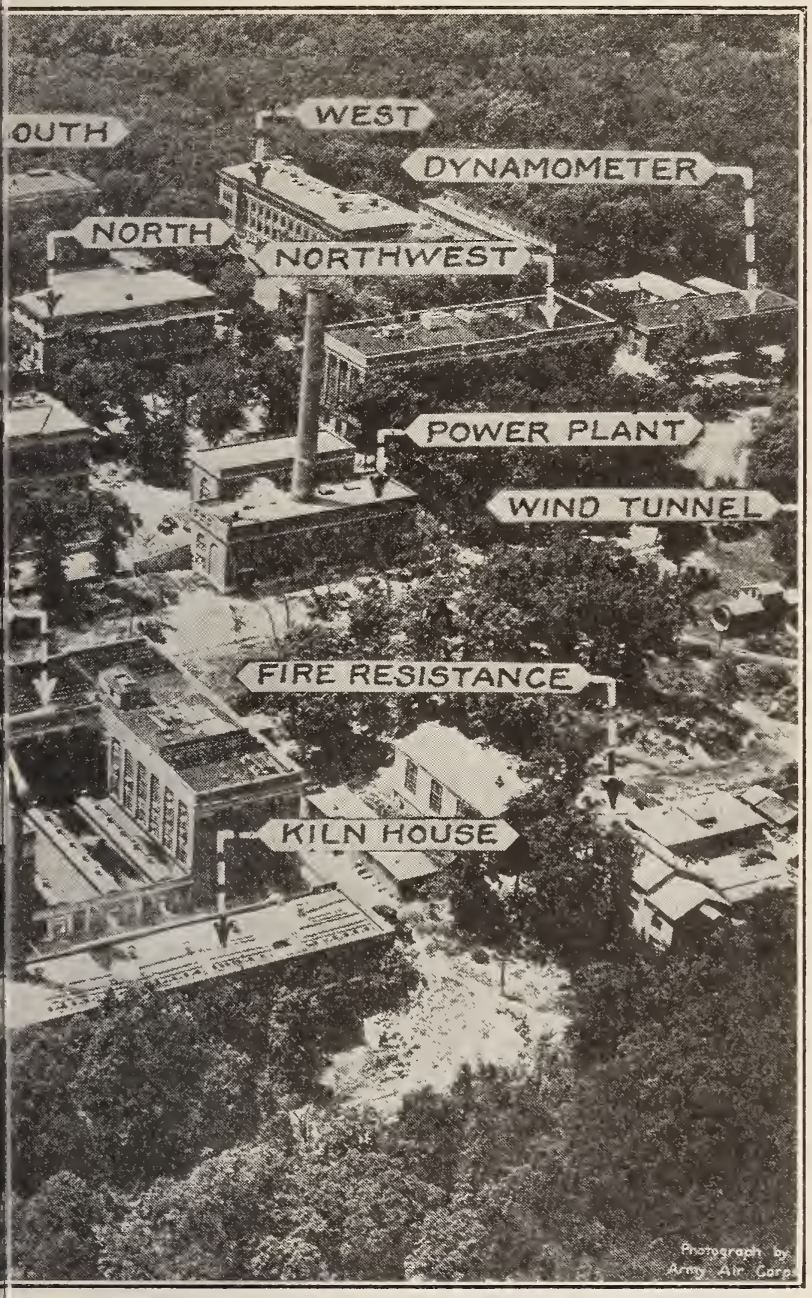

nal Bureau of Standards

South]

ureau's grounds is on Connecticut A venue, to the left of this picture. The om 300, South Building, shown near the top center. 


$$
\text { . }
$$


CHEMISTRY BUILDING-Continued

Room 417-Protective coatings

Chamber large enough for a man to work in, where humidity can be controlled by saturated solutions of salts.

(Note.-A special mimeographed guide to the laboratories in the Chemistry Building may be obtained on application at the Chief Chemist's office, room 215.)

\section{EAST BUILDING}

Rooms 106 and 10\%-Tests of electrical measuring instruments

Special switchboard for connecting different circuits and optical device for accurate reading of scale of instruments.

\section{Room 109-Heavy-current testing}

Tests are made up to 1,200 amperes. Current supplied from a special storage battery.

Room 111-Resistance measurements

The oil bath in which wire standards of resistance are immersed during test contains a special stirring arrangement and temperature control. Precision standards for other laboratories are thus compared at a constant temperature with the standards which represent the Bureau's basic unit of electrical resistance.

Room 307-Life tests of incandescent lamps

Each year several thousand lamps representing Government purchases of about 3,000,000 lamps per year are tested to ascertain whether they comply with the Federal specification requirements for rating and life.

Room 314 -Integrating sphere for determining the mean spherical candlepower of lamps

By means of a hollow sphere the inside surface of which is painted white, and at the center of which is placed the lamp, the total amount of light given off in all directions by any electric lamp is determined by a single measurement.

\section{Room 317-Tests of radium}

Practically all radium sold in the United States is tested in this laboratory. The rate of gamma radiation is compared by means of an electroscope with that of a standard sample. 
EAST BUILDING-Continued

Room 407-Optical instruments

Equipment for testing lenses, including photographic lenses used in airplane mapping.

Room 408-Standard cells

Weston normal saturated cells, by which the standard of voltage is maintained for the United States.

\section{RADIO BUILDING}

Main hall-Museum and library

Various types of electron tubes.

French and American radio sets used in World War.

Miscellaneous apparatus developed for research.

Publications, reports, and books.

Rooms 213-214-Standard of radio-frequency

Fundamental standard of radio-frequency, consisting of six quartz oscillators and auxiliary apparatus. Good to 1 part in $10,000,000$.

(Note.-Other parts of the radio work may be seen upon special arrangement with the section office.)

\section{HYDRAULICS BUILDING}

This building, which is 285 feet long and from 60 to 92 feet wide, contains supply and measuring basins, flumes, and pumping and metering equipment, for every variety of hydraulic investigation, including experiments with models of large structures. A maximum flow of 250 cubic feet per second is possible in the main flume, which is 12 feet square and 200 feet long. (Open to visitors on special arrangement with chief of the section.)

\section{INDUSTRIAL BUILDING}

Basement, west end-Cement and concrete testing equipment

Samples from about 70 percent of all cement which the Government buys are tested by the $\mathrm{Bu}-$ reau.

Basement, center-Large testing machines for structural materials

The vertical machine on the left, the largest in the world, has a capacity of $10,000,000$ pounds in compression. On the right is a 600,000-pound 
INDUSTRIAL BUILDING-Continued

machine for either tension or compression, and specially designed for testing beams. In the room next to this machine on the right is the Emery high-precision testing machine with a capacity of $2,300,000$ pounds in compression and $1,150,000$ pounds in tension.

Room 25-Optical glass

Examples of glass produced by the Bureau. Examination for striae and strain.

Room 106-Textiles

The equipment includes many special machines for determining properties of textiles. Tests of textiles and paper are made in a room in which the humidity and temperature are automatically kept constant.

Room 107-Paper

The Bureau has a complete paper-making plant, including a paper machine for making a sheet 29 inches in width, with which improvements in processes and the use of new materials can be studied.

Room 227-Rubber

The work of this section occupies several laboratories on this floor and in the basement. Automobile tires are tested for power loss and endurance, on special machines which greatly shorten the time needed for a test under simulated service conditions.

\section{Room 319-Leather}

Samples of leather made from various kinds of hides. Machine for measuring the durability of sole leather. Work on tanning solutions. Means for increasing the life of leather, and for combating deteriorating influences, such as sulphuric acid in the atmosphere, receive particular attention.

\section{KILN BUILDING}

East end-Optical-glass plant

The Bureau operates one of the few plants now making optical glass in the United States. Most of the glass made here is used by the Navy Department for binoculars, gun sights, periscopes, and similar devices. Equipment includes machinery for making pots, melting and annealing furnaces, and instruments for determining quality of glass. 
Center

KILN BUILDING-Continued

Furnaces for ceramic material, enameling of metals.

\section{West end}

Rotary cement kiln and ball mills for experimenta] grinding of cement.

\section{FIRE-RESISTANCE GROUP}

West of the Industrial Building is a group of structures in which tests are made to determine the intensity and duration of fires and the fire resistance of building materials and constructions. The equipment includes a large furnace for wall panels and another for testing safes.

\section{TEN-FOOT WIND TUNNEL}

This outdoor wind tunnel, located just west of the fire-resistance group, has a diameter of 10 feet and a maximum wind speed of 75 miles per hour. Tests on large models of buildings, chimneys, full-sized airplane wing sections, etc., are made in this tunnel.

\section{A FEW NOTABLE ACCOMPLISHMENTS}

The National Bureau of Standards-

Constructed the first altitude laboratory for measuring the performance of airplane engines under flight conditions.

Produced the first practicable model of the earthinductor compass for aircraft.

Developed the radiobeacon which, in combination with a special aerial and receiving set on the airplane, gives the pilot a visual switchboard indication of whether he is following the correct course.

Discovered that a thin coating of pure aluminum will greatly decrease the atmospheric corrosion of duralumin, a special light alloy largely used in aircraft construction.

Worked out successful process for plating steel and other metals with chromium, the hardest metal known, thus prolonging the life of gages, printing plates, and other mechanical parts several hundred percent.

Developed the paper now used for printing United States currency. Total service life extended 300 percent. 
Discovered that certain waste water from paper mills makes a satisfactory material for tanning leather.

Established the dextrose (corn sugar) industry.

Made three standards for planeness for testing gages, flat to within 1 five-millionth of an inch.

Ruled steel scales free from any measurable error.

Commenced experiments in making optical glass in 1914 and at last solved the difficult technique, so that optical glass of many grades is now produced as a routine matter.

Assisted in securing the adoption of a uniform international temperature scale by the International Conference on Weights and Measures.

Published books on house construction and repair, home ownership, zoning regulations, and plumbing requirements.

Helped to eliminate unnecessary variety of sizes and styles of over 150 articles in common use, securing agreement of manufacturers to concentrate on production of those in greatest demand, thus lowering cost of manufacture and distribution.

Assisted industry in agreeing in satisfactory standards of quality for many products, and published the results as commercial standards.

Published National Directory of Commodity Specifications and developed certification and labeling plan for making available to both large and small purchasers the benefits of buying by specification.

\section{NUMBER OF PUBLICATIONS ISSUED}

During the fiscal year 1935 the number of papers published in the Journal of Research of the National Bureau of Standards was 113. In addition, the Technical News Bulletin was issued each month. Over 30 papers were published in other series of the Bureau, including Simplified Practice Recommendations, Commercial Standards, Circulars, Handbooks, and Miscellaneous Publications. In addition, approximately 100 papers were published in outside scientific and technical journals. 


\section{VOLUME OF TESTING}

In one year the National Bureau of Standards tested approximately-

1,550 electrical standards and instruments.

1,540 electric batteries.

4,500 electric lamps, representing purchases of 2,500,000 lamps by the Government.

1,150 gages and samples of gage steel.

6,300 weights and balances.

1,460 scales.

750 timepieces.

11,200 pieces of glass volumetric apparatus.

820 hydrometers.

1,440 laboratory thermometers.

62,000 clinical thermometers.

1,850 samples of engine fuels and lubricants.

2,770 samples of sugar.

2,260 samples of radium and radioactive materials determining a sale price of $\$ 1,500$,000 .

1,135 engineering instruments.

700 aerouautic instruments.

1,070 specimens of engineering materials.

300 fusible boiler plugs.

900 samples of metals and alloys.

32,600 samples of cement and concrete, representing purchases of $4,770,000$ barrels of cement.

8,000 miscellaneous samples of ceramic materials.

1,600 samples of rubber.

5,230 samples of textile materials.

1,500 samples of paper.

1,700 samples of leather.

7,000 samples of paint and varnish.

In addition to the above, 930 miscellaneous chemical tests were made and 5,150 standard samples wore distributed. 



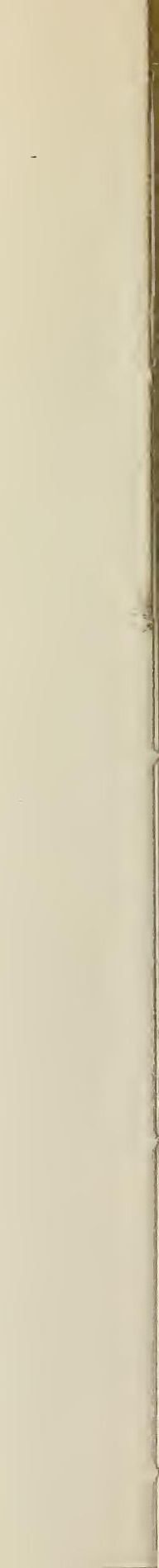


$2 x, 153$ 


\section{,}

